\title{
Biology of the conifer needle scale, Nuculaspis abietis (Hemiptera: Diaspididae), in northern Iran and parasitism by Aspidiotiphagus citrinus (Hymenoptera: Aphelinidae)
}

\author{
ARASH RASEKH ${ }^{1}$, J.P. MICHAUD ${ }^{2}$ and HASSAN BARIMANI VARANDI ${ }^{3}$ \\ ${ }^{1}$ Department of Plant Protection, College of Agriculture, Shahid Chamran University of Ahvaz, Ahvaz, Iran \\ ${ }^{2}$ Kansas State University, Agricultural Research Center - Hays, 1232 240th Ave, Hays, KS 67601, USA; e-mail: jpmi@ksu.edu \\ ${ }^{3}$ Department of Natural Resources, Agricultural and Natural Resources Research Centre of Mazandaran, Sari, Iran
}

Key words. Nuculaspis abietis, Diaspididae, Hemiptera, Aspidiotiphagus citrinus, Aphelinidae, Hymenoptera, Picea abies, Norway spruce, development, host range, parasitism, Iran

\begin{abstract}
The conifer needle scale, Nuculaspis abietis (Schrank) emerged as an important pest of conifers in the Kelardasht region of Mazandaran province, Iran, in the late 1990's. This pest feeds on conifer needles and twigs causing needle drop and branch desiccation. Its discovery in Kelardasht in Mazandaran Province necessitated a local quarantine of conifers in the genera Picea, Abies, and Pinus. We studied the life history and ecology of this scale on Norway spruce, Picea abies, under laboratory and natural field conditions. The complete life cycle of females required $206.4 \pm 5.7$ days in the laboratory $\left(25 \pm 1{ }^{\circ} \mathrm{C}, 65-75 \% \mathrm{RH}, 14 \mathrm{~L}: 10 \mathrm{D}\right)$ and $315.7 \pm$ 9.3 days under field conditions. In Kelardasht, numbers of adult males and females peaked in mid-June and early May, respectively, and numbers of first and second instar nymphs in mid-July and early September. Lifetime fecundity was estimated to be $57.3 \pm 5.1$ eggs and $54.0 \pm 4.4$ nymphs per female under laboratory conditions. The sex ratio ranged from $59 \%$ female for second instar nymphs to $71 \%$ female for adults. Aspidiotiphagus citrinus (Crawford) (Hymenoptera: Aphelinidae) was found naturally parasitizing the scale and overwintering in the larval stage on second instar nymphs. First generation adult wasps emerged in spring from overwintered second instar nymphs to parasitize $64.75 \%$ of first instar scales. Second generation wasps emerged from early September to mid-October and parasitized $19.75 \%$ of second instar scales, for a cumulative parasitism rate of $84.5 \%$.
\end{abstract}

\section{INTRODUCTION}

The conifer needle scale, Nuculaspis abietis (Schrank) (= Coccus abietis, Aspidiotus abietis) (Danzig, 1967) is known to attack conifers from the genera Abies, Juniperus, Picea, Pinus, and Pseudotsuga in Europe, Russia, and North America (Danzig, 1993). Borchsenius (1939) described the second instar nymph and Graf \& Weber (1996) described the damage done by this pest to Pinus sylvestris L. In southern Germany, N. abietis has one generation per year and hibernates as a second instar nymph (Kostarab \& Kozar, 1988), but little else is known about the biology of this insect. In 1995, N. abietis was reported in the Kelardasht region on blue and green Norway spruce (Picea pungens and P. abies), its first record in Iran (Abai, 1995). Given the pest's absence from other regions of Mazandaran province, a regional quarantine was imposed on trees of the genera Picea, Abies, and Pinus in Kelardasht.

The Norway spruce, Picea abies (L.), is a large tree that can reach $40 \mathrm{~m}$ in height and $>100 \mathrm{~cm}$ dbh (diameter at breast height). The natural range of this tree encompasses most of northern, central, and southern Europe but it is largely restricted to montane habitat (elevations above $400 \mathrm{~m}$ ) south of $47^{\circ} \mathrm{N}$ latitude. An ecologically flexible species (Platonova, 2004), it prefers a cool climate and abundant rainfall (Banan \& Fazilat, 1984). Norway spruce was planted for the first time in Kelardasht, Lagim and Sangedeh (Mazandaran Province, Iran) on 75-80 ha of land in the 1970's (Mirbadin \& Sagheb, 1991). Since that time, it has been planted extensively in governmentsponsored reforestation projects in northern Iran and has become popular as an ornamental tree in urban settings.

The primary objective of this investigation was to characterize the biology and seasonal population dynamics of the conifer needle scale on Norway spruce in Mazandaran Province. Secondary objectives were to survey patterns of host use in the area and identify any parasitoids of N. abietis that might be present.

\section{MATERIAL AND METHODS}

\section{Study location}

Kelardasht is located in the province of Mazandaran in northern Iran, $55 \mathrm{~km}$ south of the Caspian Sea at $1200 \mathrm{~m}$ a.s.1. Yearly rainfall averages $496 \mathrm{~mm}$, and the climate is cool and humid (Mirbadin \& Sagheb, 1991).

\section{Morphological description of life stages}

A series of Norway spruce terminals bearing $N$. abietis were collected from naturally infested trees in Kelardasht. A total of 40 individuals of each representative life stage were examined, measured and photographed in order to characterize distinguishing features.

\section{Development under laboratory and field conditions}

Two year-old potted Norway spruce saplings $(n=10)$ were obtained from the Kelardasht Tree Nursery and held in a growth chamber at $25 \pm 1{ }^{\circ} \mathrm{C}, 65-75 \% \mathrm{RH}$, and a $14 \mathrm{~L}: 10 \mathrm{D}$ photoperiod under fluorescent lighting. Infestation was accomplished by 

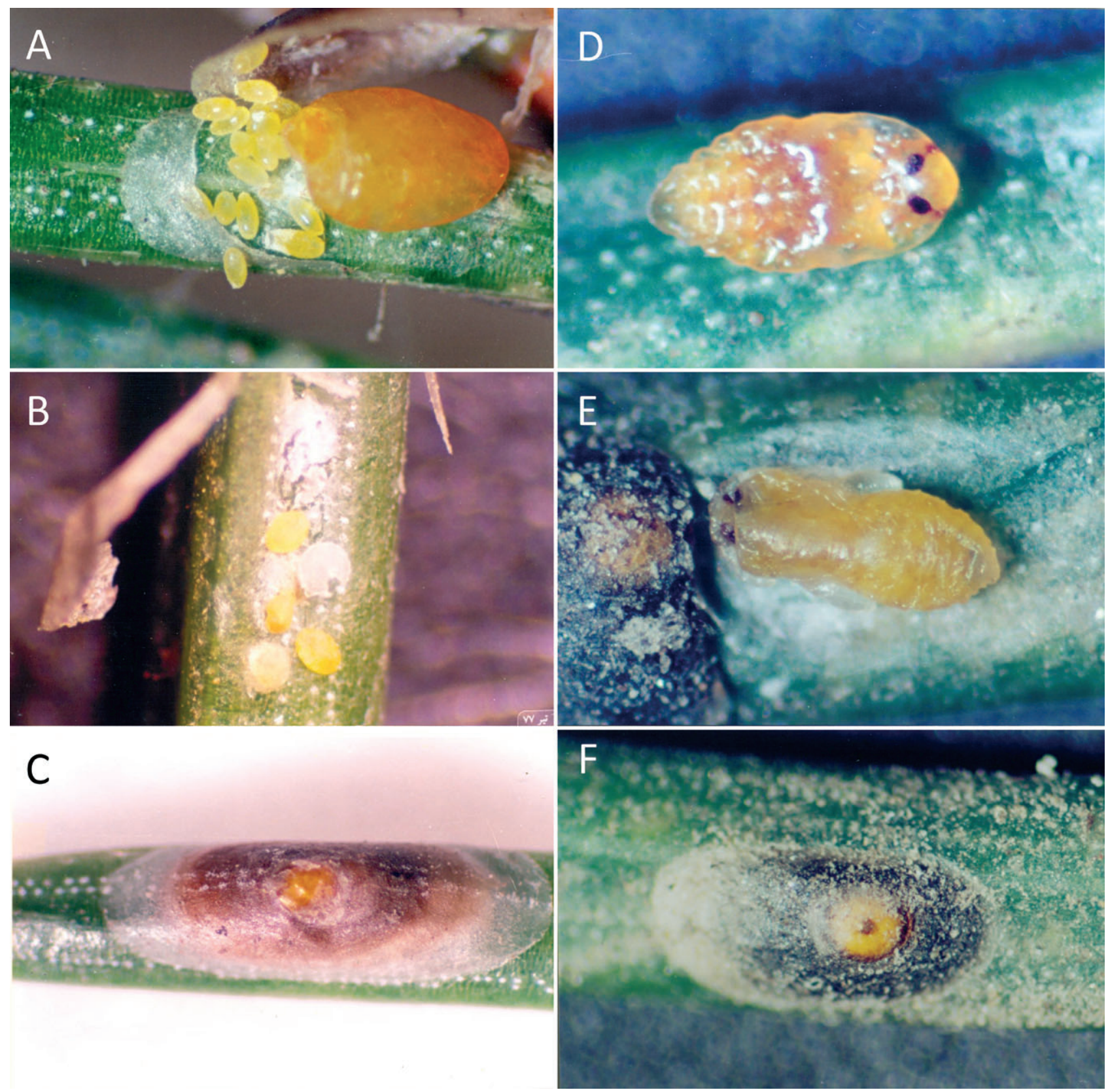

Fig. 1. Stages of Nuculaspis abietis. A - gravid female exposed with eggs and crawlers; B - settled first instar nymphs (crawlers), two with first scale secreted; $\mathrm{C}$ - mature female under scale; D - male second instar nymph; E - male prepupa; F - mature male under scale.

placing a branch with crawlers of $N$. abietis onto each sapling for a period of two weeks. After the crawlers had settled, 20 nymphs on each sapling were marked by attaching numbered tags to needles bearing one or two nymphs each. Nymphs were sexed in second nymphal instar, the first stage at which gender can be distinguished. All tagged nymphs were examined under a hand lens daily during the first instar, and weekly thereafter, to monitor their development. All sampling was non-destructive. The first molt is clearly discernable as an abrupt color change to orange as the shed exuvia adhers to the scale cover. Thereafter, the scale does not adher to the body of the insect and was carefuly raised from one edge with a dissecting needle to detect oviposition by females and pupation by males. Scale covers were then replaced with care so as not to harm the insects beneath.
We determined the developmental period under field conditions following the method of McClure (1985). Four infested Norway spruce trees in Kelardasht were sampled weekly from January to December, 2000, by removing one infected branch from each tree. Branches were taken to the laboratory and ten insects were dissected from each branch under a stereomicroscope to determine their growth stages. Mean numbers of insects in each growth stage were then calculated from the average counts of each stage on all four branches.

\section{Reproductive biology}

In order to estimate female egg load, we collected infested branches from Norway spruce trees in the Kelardasht treenursery in early June, 2000, and transported them to the laboratory. There, we dissected out the ovaries of gravid females $(\mathrm{n}=$ 100) in a drop of saline solution on a microscope slide under a 
TABLE 1. Mean ( \pm SEM) duration (in days) of immature life stages of $N$. abietis raised $(\mathrm{n}=200)$ on Norway spruce saplings under controlled laboratory conditions of $25 \pm 1^{\circ} \mathrm{C}, 65-75 \% \mathrm{RH}$, and 14L : 10D photoperiod and those observed on established Norway spruce trees under field conditions in Kelardasht, Iran, in 2000 .

\begin{tabular}{lcc}
\hline Life stage & Females & Males \\
\hline \multicolumn{3}{c}{ Laboratory } \\
Egg & \multicolumn{2}{c}{$4.1 \pm 0.2$} \\
First instar nymph & $153.8 \pm 3.5$ & $174.6 \pm 2.2$ \\
Second instar nymph & $27.3 \pm 2.5$ & $6.1 \pm 0.2$ \\
Third instar nymph / prepupa & $10.0 \pm 1.1$ \\
Pupa & $206.4 \pm 5.7$ & $215.2 \pm 4.9$ \\
Total & Field \\
\hline \multicolumn{2}{c}{$7.1 \pm 0.5$} \\
Egg & $29.2 \pm 1.4$ \\
First instar nymph & $279.5 \pm 4.2$ \\
Second instar nymph & $57.9 \pm 3.2$ & $273.7 \pm 4.1$ \\
Third instar nymph / prepupa & $7.5 \pm 0.8$ \\
Pupa & \multicolumn{2}{c}{$14.2 \pm 1.4$} \\
Total & $315.7 \pm 9.3$ & $329.4 \pm 8.7$ \\
\hline
\end{tabular}

stereomicroscope as described by McClure (1983). To determine fertility, gravid females $(\mathrm{n}=30)$ were each isolated on an excised twig of $P$. abies in a Petri dish $(11 \mathrm{~cm}$ diam. $\times 1 \mathrm{~cm} \mathrm{ht}$. held in a growth chamber under the same conditions as described above. To preserve plant condition, the ends of the twigs were encased in a balls of moistened cotton that were refreshed every second day. To prevent the escape of crawlers, the edges of each Petri dish was glued closed. The number of eclosing crawlers were counted and removed daily and the dishes re-sealed after each observation.

Realized female fecundity was assessed in a separate trial. Gravid females $(\mathrm{n}=30)$ were each placed on a twig of $P$. abies in a glass tube $(2.4 \mathrm{~cm}$ diam. $\times 10 \mathrm{~cm} \mathrm{ht}$.). The ends of the twigs were embedded in balls of moist cotton. Each day, the female's scale was partially raised and all the eggs produced were removed and counted until the female died.

The sex ratio of the scale population was estimated by collecting branches from the aforementioned infested trees, selected to bear suitable numbers of either second instar nymphs $(n=10)$ or adults $(n=10)$. Both life stages were then sexed by observing 100 individuals from each branch under the stereomicroscope.

\section{Host range and local distribution}

The distribution of $N$. abietis in Mazandaran was determined by inspecting potential coniferous host plants in various regions of the province from early April to early June, 2000. Three sites at least one kilometer apart were sampled in each region and a minimum of 10 trees of each species were inspected at each site. To estimate the relative susceptibility of the primary host species, one branch was collected from each of three infested trees of Picea abies, Picea pungens, Picea nordmanniana, Abies alba and Abies nordmanniana in the Kelardasht tree nursery in early September, 2000. These were transported to the laboratory where all second instar nymphs were counted on 100 needles of each branch under a stereomicroscope.

\section{Seasonal population dynamics}

From December 1999 to December 2000, one branch was sampled weekly from each of four infested Norway spruce trees near Kelardasht. Following transportation to the laboratory, all scale life stages were counted on 100 needles of each branch under a stereomicroscope as described by Kostarab \& Kozar (1988). These data were used to estimate seasonal scale population dynamics.

\section{Parasitism}

A single branch was cut weekly from each of four Norway spruce trees and taken to the laboratory where infested plant parts were excised and held in glass tubes (as described above). The containers were kept in a growth chamber, under the conditions described above, until the emergence of parasitoids.

We determined percentage parasitism using the method of McClure (1983). One branch was cut weekly from each of the four infested $P$. abies trees and a sample of 100 nymphal scales from each branch was selected at random. These were examined under a stereomicroscope to determine the presence of parasitism. Percent parasitism was calculated as the sum of parasitized scales plus those with emergence holes, divided by the total number of scales, and multiplied by 100 . This approach is expected to slightly underestimate actual rates of parasitism because eggs are not directly observable. However, it was possible to distinguish emerged mummies of the first and second generations.

\section{RESULTS}

\section{Morphological description of life stages}

Eggs of $N$. abietis averaged $0.23 \pm 0.02 \mathrm{~mm}$ (mean \pm SEM) in length by $0.13 \pm 0.01 \mathrm{~mm}$ in width. As they are

TABLE 2. Locations and tree species inspected for N. abietis in Mazandaran province, Iran, in 2000. The underscored species were positive for scale.

\begin{tabular}{|c|c|c|}
\hline Region & Elevation (m a.s.1.) & Tree species \\
\hline Kelardasht & $1,150-1,500$ & 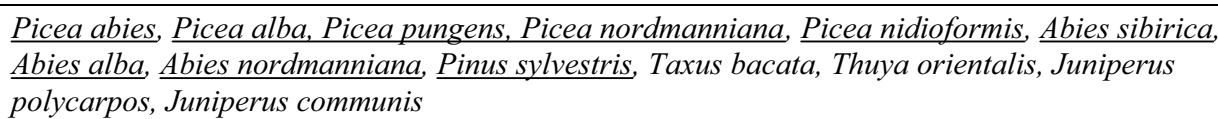 \\
\hline Noshahr & -20 & $\begin{array}{l}\text { Picea abies, Picea pungens, Picea nordmanniana, Picea nidioformis, Abies alba, Abies } \\
\text { nordmanniana, Pinus sylvestris, Thuya orientalis, Juniperus polycarpos, Juniperus communis }\end{array}$ \\
\hline Ramsar & -21 & Thuya orientalis \\
\hline Babolsar & -20 & Thuya orientalis \\
\hline Sari & 40 & Picea abies, Pinus sylvestris, Thuya orientalis, Pinus radiata, Pinus nigra \\
\hline Lagim & 950 & Juniperus polycarpos, Abies alba, Picea abies \\
\hline Necka & 65 & Pinus sylvestris \\
\hline Behshahr & 120 & $\begin{array}{l}\text { Cupressus arizonica, Thuya orientalis, Pinus eldarica, Pinus nigra, Cedrus libani, Cedrus deo- } \\
\text { dara, Cupressus sempervirens var. horizontalis, Taxus bacata }\end{array}$ \\
\hline Hezar-Jarib & 1,200 & Juniperus polycarpos, Juniperus communis \\
\hline
\end{tabular}




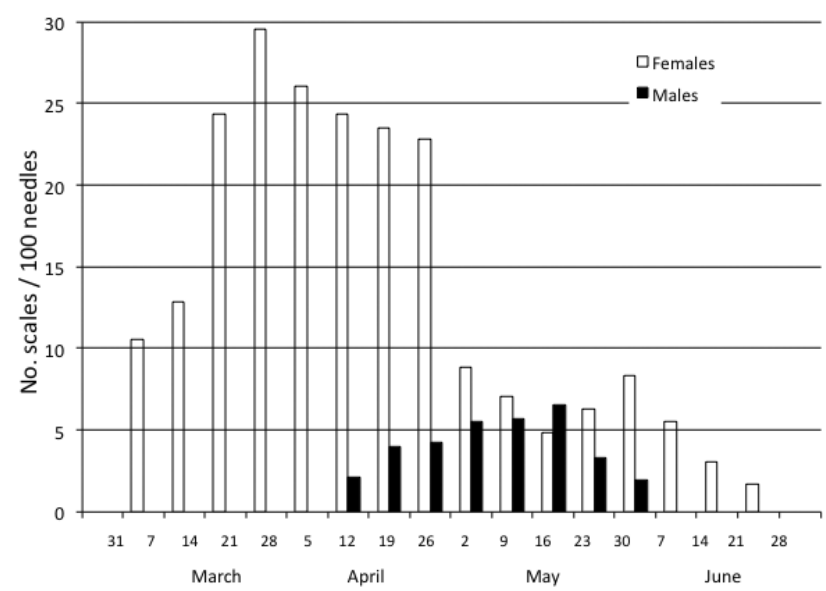

Fig. 2. Mean numbers of adult $N$. abietis scales per 100 needles on trees of Norway spruce $(n=4)$ in Kelardasht, Iran, 2000 .

laid, the oval eggs are yellowish orange, soft and attached together in a string. As the eggs dry, they separate and become paler in color. Ocular points become visible on the eggs one or two days prior to eclosion. The emergence of first instar nymphs, or crawlers, requires $70 \pm 20$ $\min (\mathrm{n}=30)($ Fig. 1A). Crawlers average $0.24 \pm 0.02 \mathrm{~mm}$ in length by $0.14 \pm 0.01 \mathrm{~mm}$ in width. They are yellow, oval in shape, with antennae and three pairs of legs. Shortly after settling, crawlers secrete a white cap, the first scale (mean $=0.48 \pm 0.01 \mathrm{~mm}$ in length by $0.33 \pm$ $0.01 \mathrm{~mm}$ in width; Fig. 1B) that gradually changes to orange in the nipple stage. The gender of crawlers cannot be distinguished by visual inspection.

The female second instar nymph is oval in shape and pale yellow in color with indistinct abdominal segmentation. The scale is brown or pale brown and averages 1.66 $\pm 0.04 \mathrm{~mm}$ in length by $0.62 \pm 0.02 \mathrm{~mm}$ in width. In comparison, the male second instar nymph is spindle-shaped, dark yellow in color, has distinct abdominal segmentation, and ocular points clearly visible on the head (Fig. 1D). The scale is dark brown or black and averages 1.65 $\pm 0.03 \mathrm{~mm}$ in length by $0.61 \pm 0.01 \mathrm{~mm}$ in width. The male insect secretes a silk wax underneath the scale, whereas no such silk is secreted by females.

The female third instar nymph, or virgin adult, averaged $0.79 \pm 0.02 \mathrm{~mm}$ in length by $0.50 \pm 0.02 \mathrm{~mm}$ in width. These are oval in shape, yellow in color, have indistinct abdominal segmentation, and secrete a third white scale that male insects do not. In contrast, male insects pass through prepupal and pupal phases. The prepupa averages $0.82 \pm 0.02 \mathrm{~mm}$ in length by $0.48 \pm 0.02$ $\mathrm{mm}$ in width, is spindle-shaped and dark yellow with two pairs of ocular points on the head, one pair on the frons and one pair on the ventral surface of the head (Fig. 1E). The pupa is spindle-shaped, dark yellow, and averages $1.02 \pm 0.04 \mathrm{~mm}$ in length by $0.36 \pm 0.01 \mathrm{~mm}$ in width.

In the mature adult female (Fig. 1C), both the body and the scale are larger than in virgin females, (body mean $=$ $1.72 \pm 0.01 \mathrm{~mm}$ in length by $0.55 \pm 0.01 \mathrm{~mm}$ in width; scale mean $=2.70 \pm 0.03 \mathrm{~mm}$ in length by $0.79 \pm 0.01$

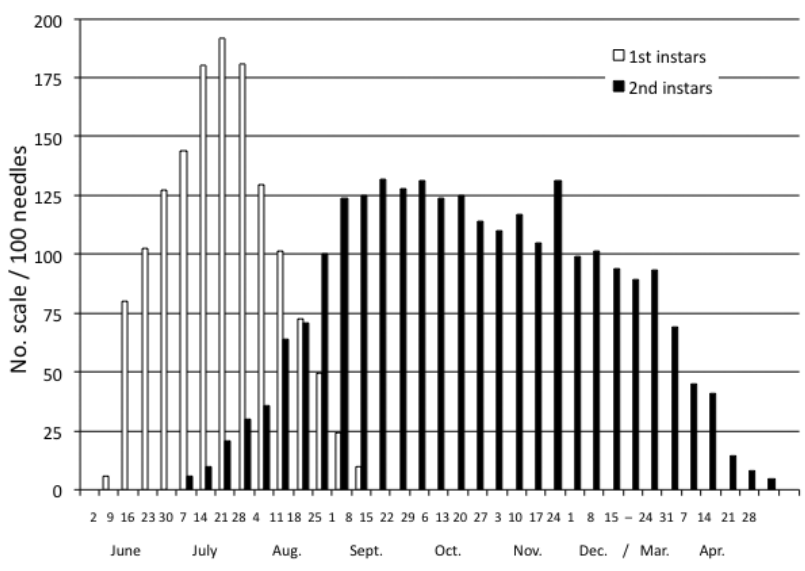

Fig. 3. Mean numbers of $N$. abietis first instar (crawlers) and second instar nymphs per 100 needles on trees of Norway spruce $(n=4)$ in Kelardasht, Iran, 2000.

$\mathrm{mm}$ in width). Once gravid, the female ceases growth and honeydew secretion. The free-living adult male lacks functional mouthparts, is spindle-shaped (mean $=1.08 \pm$ $0.03 \mathrm{~mm}$ in length), yellow with a wide black band on thorax and possesses a single pair of clear wings, one pair of ocelli, antennae with 10 segments, and a penis $(0.24 \pm$ $0.01 \mathrm{~mm}$ in length). Since neither the prepupae nor the pupae of males secrete a scale, these stages remain under the scale of the second instar nymph until emergence of the mature adult.

\section{Development under laboratory and field conditions}

The mean durations of immature life stages and total developmental times for female and male insects were considerably shorter under laboratory conditions than under the field conditions prevailing in Kelardasht in 1999 (Table 1). Males took nine and 14 days longer to complete development than did females in the two studies, respectively. The longevity of adult females under natural conditions was $31.6 \pm 5.7$ days.

\section{Reproductive biology}

As is generally true for most diaspidid species, the embryonic development of eggs is staggered in accordance with their sequence of oviposition and is temperature-dependent, the eclosion of crawlers requiring anywhere from a number of hours to eight days (AR, personal observation). Consequently, both egg and first instar nymphs are often seen together under the same adult female's scale. Newly eclosed nymphs leave the scales and settle on needles within 6-12 h, although a few sometimes settle underneath their mother's scale. Under field conditions in Kelardasht, the oviposition period ranged from 16 to 32 days (mean $=18.7 \pm 1.4 \mathrm{~d}, \mathrm{n}=30$ ).

Dissections of gravid females collected from infested branches revealed egg loads ranging from 41 to 74 eggs $($ mean $=64.2 \pm 5.2)$. In the fecundity trial, females $(n=$ 30) laid an average of $6.5 \pm 1.7$ eggs per day (range $=$ 3-14) for an average of $12.3 \pm 2.1$ days, yielding an average lifetime fecundity of $57.3 \pm 5.1$ eggs (range $=$ 32-64). Collection of dispersing crawlers from Petri dishes yielded a mean of $54.0 \pm 4.4$ nymphs per female ( $\mathrm{n}$ 


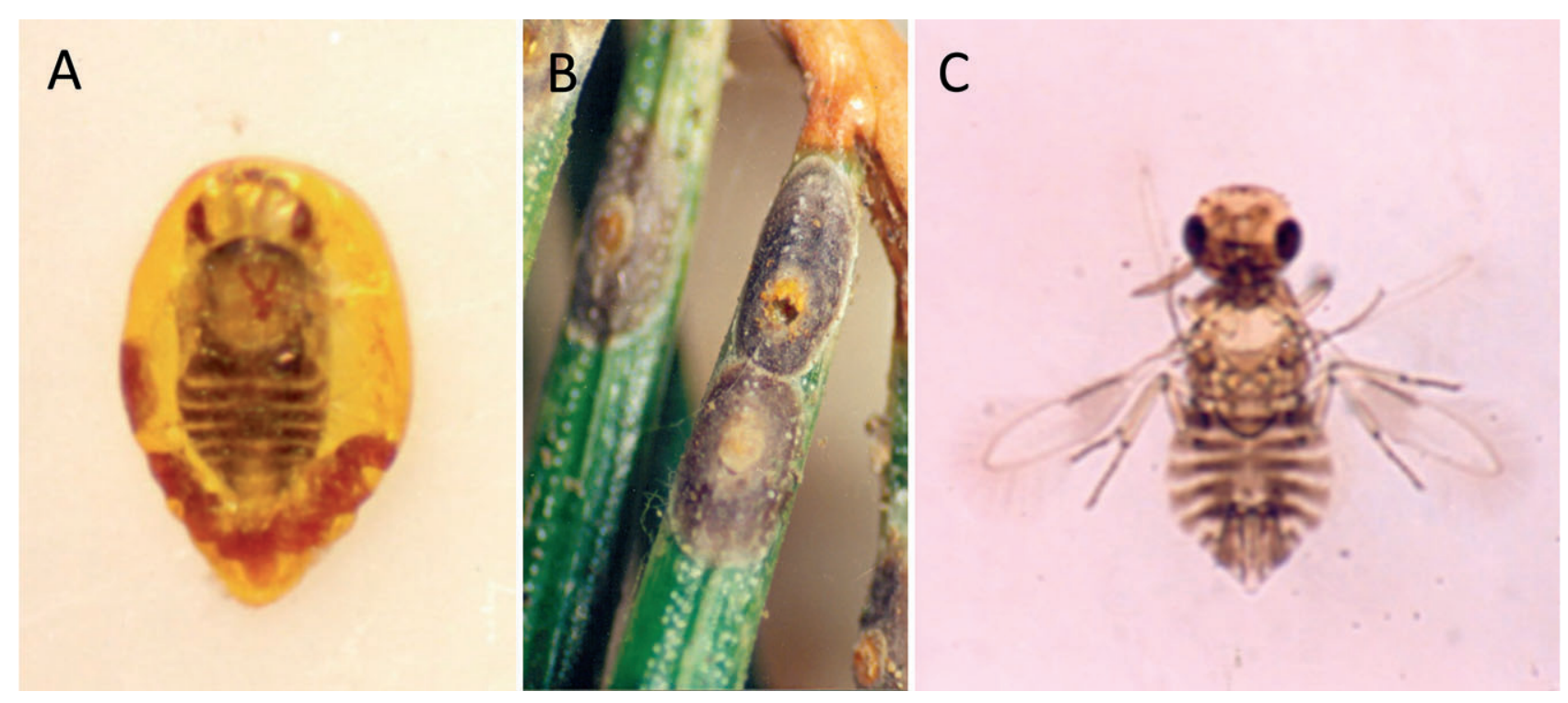

Fig. 4. Aspidiotiphagus citrinus, a parasitoid of N. abietis. A - pupa within host scale; B - scale with exit hole; $\mathrm{C}$ - adult wasp.

$=30$ ), suggesting that egg fertility was very high. The sex ratio was female-biased in both second instar nymphs $(0.59)$ and adults $(0.71)$, but neither of these values represented significant departures from 0.5 (Chi square, Goodness-of-fit, $\alpha=0.05$ ).

\section{Host range and local distribution}

The survey revealed that $N$. abietis was absent from all sampled regions of Mazandaran province except for Kelardasht, where it occurred primarily on species of Picea and Abies (Table 2). The nursery samples revealed significant variation among tree species $\left(\mathrm{F}_{4,10}=276.82, \mathrm{P}\right.$ $<0.001)$ in numbers of scale per 100 needles, P. abies and $P$. pungens bearing significantly more (Tukey HSD, $\alpha=0.05)$ than the other species that were not different from each other (Mean \pm SE, P. abies: $123 \pm 4.3$, P. pungens: $118 \pm 5.2, P$. nordmanniana: $23 \pm 3.0, P$. alba: $15 \pm$ 1.7, and A. nordmanniana: $11 \pm 1.5$ ).

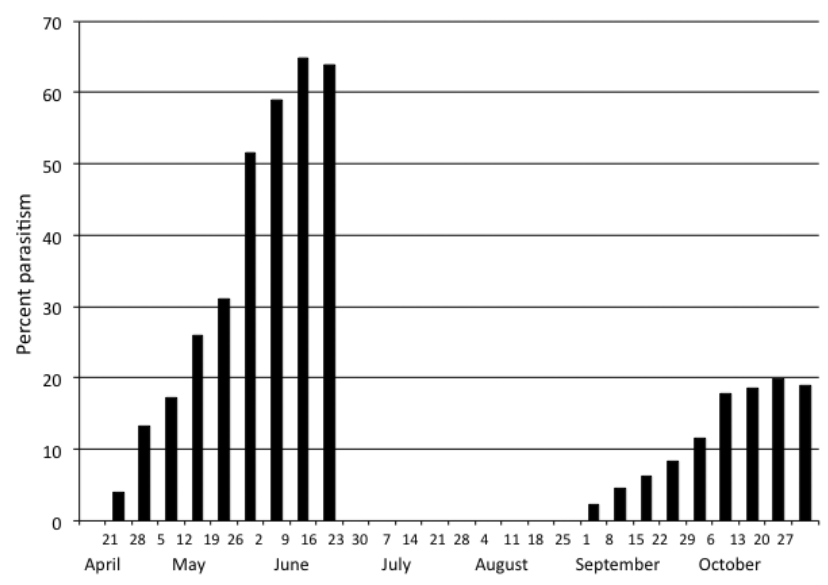

Fig. 5. Percentage parasitism of $N$. abietis by first (April July) and second (September - October) generation A. citrinus on trees of Norway spruce $(\mathrm{n}=100$ scales sampled on each of 4 trees) in Kelardasht, Iran, 2000.

\section{Seasonal abundance}

Nuculaspis abietis was observed to complete one generation per year in Kelardasht, hibernating as a second instar nymph. Adult females first appeared in early April, peaked in abundance in late April, and had disappeared by late July (Fig. 2). Male second instars became prepupa in late April and pupation was observed in early May. Adult males peaked in abundance in the middle of June and had largely disappeared by the beginning of July.

Oviposition began in late May and the number of eggs and neonate crawlers found under scales peaked in early June at $777.3 \pm 62.4$ per 100 needles. First instar nymphs began settling on needles at the beginning of June and reached peak abundance in the middle of July, whereas second instar nymphs were first observed in late June and peaked in abundance in early September (Fig. 3). The mean oviposition period under field conditions was 18.7 \pm 1.4 days $($ minimum $=16$, maximum $=23, \mathrm{n}=30$ ).

\section{Parasitism}

The only parasitoid species emerging from samples was Aspidiotiphagus citrinus (Crawford) (Hymenoptera: Aphelinidae) (Fig. 4). The wasp larva develops as a solitary ectoparasitoid, although superparasitism can occur and in one case we observed two larvae in a single scale host. In the Kelardasht region, A. citrinus has two generations per year. Overwintered wasps emerged as adults from the end of April until late June and began attacking first instar nymphs of $N$. abietis in May (Fig. 5). Wasps of the second generation emerged over a period from early September to mid October and attacked second instar $N$. abietis beginning in early September, their progeny overwintering as larvae on their hosts.

Under field conditions in Kelardasht, cumulative parasitism of N. abietis by first (overwintered) generation $A$. citrinus reached $64.75 \%$ by the middle of June when all second generation wasps had emerged from their hosts. Wasps of the second generation parasitized $19.75 \%$ of 
scales from early September until late October, for a cumulative parasitism rate of $84.5 \%$.

\section{DISCUSSION}

Our results indicate that $N$. abietis has one generation per year in northern Iran, primarily feeding on species of Picea (P. abies, $P$. alba, $P$. pungens, $P$. nordmanniana and $P$. nidioformis) and Abies (A. sibirica, A. alba and $A$. nordmanniana). Although Pinus sylvestris may also be attacked, the specimens of Juniperus, Thuya and Taxus spp. that we examined in the infested region of Kelardasht were not. Scale outbreaks are often confined to one host species even when other host species occur in the area (Edmunds, 1973; McClure, 1986). This is thought to occur because nymphal survival is typically highest on the parent tree, lower on other trees of the same species, and very low on host trees of other species. Based on the samples obtained from the infested nursery, both $P$. abies and $P$. pungens appear to be preferred in northern Iran and should be priority targets for phytosanitary inspectors in adjacent localities.

The sex ratio of $N$. abietis was slightly female-biased in the second instar, the earliest stage in which sex determination is possible, and trended toward greater female-bias in the adult stage. Although the deviation from a 50\% sex ratio was not signficiant, the trend is suggestive of differential male mortality during the course of development. Changes in the sex ratio of black pine leaf scale, $\mathrm{Nucu-}$ laspis californica, have been infered to reflect differential mortality according to gender (Alstad et al., 1980; Alstad \& Edmunds, 1983, 1987). In the latter studies, hatching ratios were significantly female-biased, and subsequent differential mortality further increased this bias prior to emergence of adult males. In addition, Edmunds \& Alstad (1985) showed that haploid males of $N$. californica were more sensitive to malathion than diploid females, so insecticide applications may have the potential to further skew sex ratios in these insects.

Reported parasitoids of $N$. abietis include Aphytis abnormis (Howard), A. mytilaspidis (Le Baron), Prospaltella aspidioticola Mercet, P. aurantii (Howard), P. gigas Chumakova, P. leucaspidis Mercet, Coccophagus similis (Masi) (Kostarab \& Kozar, 1988) and Encarsia aspidioticola Mercet (Battaglia \& Viggiani, 1985). Aspidiotiphagus citrinus is known to attack a range of diaspidid scale species (Tao \& Chang, 1963; Walker \& Deitz, 1979), including other species of Nuculaspis (McClure, 2002), but this is the first report of it attacking $N$. abietis. Although this species regularly parasitizes more than $90 \%$ of Fiorinia externa Ferris and Nuculaspis tsugae (Marlatt) in Japan, it has been less effective in the eastern United States (McClure, 1986). In Kyoto, Japan, $A$. citrinus and its scale hosts both have two generations per year and the emergence of adult parasitoids is well synchronized with the peak abundance of vulnerable scale stages (McClure, 1986). However, in Connecticut, USA where $F$. externa completes only one generation a year (McClure, 1978) the peak emergence of bivoltine $A$. citrinus occurs almost eight weeks after the peak abun- dance of $F$. externa second instar nymphs. This results in highly variable parasitism rates from year to year and equilbrium scale densities much higher than observed in Japan. However, because $N$. tsugae completes two generations per year in Connecticut, its life cycle is more synchronous with that of $A$. citrinus and parasitism rates around $55 \%$ are sustained (McClure, 1986). Despite the fact that $N$. abietis has one generation in Kelardasht while A. citrinus completes two, the phenology of the scale population is such that adult parasitoids of both generations tend to encounter vulnerable stages of $N$. abietis, at least in the year of this study. Although it is conceivable that aberrant weather conditions could desynchronize the parasitoid and scale populations in some years, parasitoids that complete two or more generations in the period required for their host to complete one are considered to possess a favorable "generation time ratio" (Kindlmann \& Dixon, 1999), a situation generally viewed as auspicious for biological control outcomes. For example, excellent biological control of the pseudococcid Maconellicoccus hirsutus Green has been obtained with Anagyrus kamali Moursi and Gyranusoidea indica Shafee, Alam \& Agarwal (Hymenoptera: Encyrtidae) and this success is often attributed to the parasitoids' ability to complete two generations in the time it takes their host to complete one (Michaud, 2003).

During the course of this study, it was apparent that $N$. abietis achieved much higher densities on young trees in the Kelardasht nursery than it did on established trees in the local forests. A number of factors likely contribute to this difference. Young trees in a nursery are frequently fertilized and grow rapidly, which could make them more nutritious hosts than older, established trees. Nurseries are managed environments that receive periodic applications of herbicides and insecticides that may kill or repel parasitoids. Similarly, Yanin (1975) concluded that N. abietis and other coccids were more likely to become pests of woody ornamentals in artificial than in natural settings. Insecticide applications targeting $N$. abietis in the Kelardasht tree nursery are normally timed with the appearance of crawlers (typically in early June) and unfortunately this coincides with the peak emergence of adult parasitoids.

The study region was revisited in August, 2010 to assess the state of scale infestation some ten years after the original study. Densities of $N$. abietis on established trees were noticably reduced in comparison with the study period and the infestation still appeared to be restricted to the Kelardasht region. The scale remained detectable on established trees of Picea abies, P. pungens, $P$. orientalis, $P$. nidioformis, Abies alba and A. nordmanniana, but not at levels that would be considered economic. Scale management in the tree nursery has shifted from periodic broadcast applications of insecticides to spot-treatment of only severely affected saplings on an as-needed basis, an approach which has been successful in reducing the frequency and intensity of pesticide applications and favored the conservation of the parasitoid on untreated trees, improving the overall level of biological control. Thus, $A$. citrinus appears to make an important 
contribution to the control of $N$. abietis in Kelardasht, even though it may be necessary to supplement its impact with selective spot-treatments of insecticides in tree nurseries where young, vigorously growing trees under intensive fertilization and irrigation schedules may be particularly vulnerable.

ACKNOWLEDGEMENTS. The authors are grateful to the Agricultural and Natural Resources Research Centre of Mazandaran, Sari, for providing equipment, resources and technical support for this research.

\section{REFERENCES}

AвAI M. 1995: Report of Nuculaspis abietis (Schrank) from Mazandaran, Iran. J. Appl. Entomol. Phytopath. 62: 26, 108-109.

Alstad D.N. \& Edmunds G.F. 1983: Selection, outbreeding, depression, and sex ratio of scale insects. Science 220: 93-95.

Alstad D.N. \& Edmunds G.F. 1987: Black pine leaf scale (Homoptera: Diaspididae) population density in relation to interdemic mating. Ann. Entomol. Soc. Am. 80: 652-654.

Alstad D.N., Edmunds G.F. \& JohnSON S.C. 1980: Host adaptation, sex ratio, and flight activity in male black pineleaf scale. Ann. Entomol. Soc. Am. 73: 665-667.

Banan G.H. \& Fazilat M. 1984: Ornamental Conifers. Khodkafaee Press, Isfehan, Iran, $56 \mathrm{pp}$.

Battaglia D. \& Viggiani G. 1985: Preliminary bioethological data on Encarsia aspidioticola (Mercet) new parasite of Dynaspidiotus britannicus (Newst.) in Italy. In: Atti XIV Congresso Nazionale Italiano di Entomologia, Palermo, Italy, 28 May-1 June, pp. 337-340.

Borchsenius N.S. 1939: On the fauna of Coccidae in the Caucasus. Zashch. Rast. (Leningrad) 18: 43-51 [in Russian].

DANZIG E.M. 1967: Keys to the Insects of the European USSR. Academy of Sciences of the USSR, Leningrad, $850 \mathrm{pp}$.

Danzig E.M. 1993: Fauna of Russia and Neighbouring Countries. Nauka, St. Petersburg, 452 pp.

Edmunds G.F. 1973: Ecology of black pine leaf scale (Homoptera: Diaspididae). Environ. Entomol. 2: 765-777.

Edmunds G.F. \& Alstad D.N. 1985: Malathion induced sex ratio change in black pine leaf scale (Homoptera: Diaspididae). Ann. Entomol. Soc. Am. 78: 403-405.

GraF D. \& WeBer T. 1996: Influence of aphids on scots pine needles. AFZ Der Wald Allgem. Forst Z. Waldwirtsch. Umweltfors. 51: 392-394.
Kindlmann P. \& Dixon A.F.G. 1999. Generation time ratios determinants of prey abundance in insect predator-prey interactions. Biol. Contr. 16: 133-138.

Kostarab M. \& Kozar F. 1988: Scale Insects of Central Europe. Junk Publishers, Budapest, 456 pp.

MCCluRE M.S. 1978: Seasonal development of Fiorinia externa, Tsugaspidiotus tsugae (Homoptera: Diaspididae) and their parasite Aspidiotiphagus citrinus (Hymenoptera: Aphelinidae): Importance of parasite host synchronism to the population dynamics of two scale pests of hemlock. Environ. Entomol. 7: 863-870.

MCCLURE M.S. 1983: Reproduction and adaptation of exotic hemlock scales (Homoptera: Diaspididae) on their new and native hosts. Environ. Entomol. 12: 1811-1815.

MCCluRE M.S. 1985: Patterns of abundance, survivorship, and fecundity of Nuculaspis tsuga (Homoptera: Diaspididae) on Tsuga species in Japan in relation to elevation. Environ. Entomol. 14: 413-415.

MCCluRe M.S. 1986: Population dynamics of Japanese hemlock scales: a comparison of endemic and exotic communities. Ecology 67: 1411-1421.

MCCLURE M.S. 1989: Importance of weather to the distribution and abundance of introduced adelgid and scale insects. Agric. For. Meteorol. 47: 291-302.

MCClure M.S. 2002: The elongate hemlock scale, Fiorinia externa Ferris (Homoptera: Diaspididae): A new look at an old nemesis. In Onken B., Reardon R. \& Lashomb J. (eds): Proceedings, Hemlock Woolly Adelgid in the Eastern United States. USDA Forest Serv., East Brunswick, NJ, pp. 248-255.

Michaud J.P. 2003: Three targets of classical biological control in the Caribbean: Success, contribution, and failure. In van Driesche R. (ed.): First International Congress on Biological Control of Arthropods, Jan. 14-18, 2002, Honolulu, Hawaii. USDA Forest Service, Morgantown, WV, pp. 335-342.

Mirbadin A. \& SAGHeb TK. 1991: Afforestation successfully with Picea abies in different communities of Kelardasht region. Jang. Sen. J. 75: 36-75.

Platonova E.A. 2001: The distribution of tree species in the ridge landscape (Southern Karelia). Russ. J. Ecol. 32: 375-381.

TAo L.C. \& Chang CC. 1963: Black Parlatoria, Parlatoria zizyphus (Lucas). J. Taiwan Agric. Res. 12: 34-47.

Walker A.K. \& Deitz LL. 1979: A review of entomophagous insects in the Cook Islands. New Zeal. Entomol. 7: 70-82.

YANIN V.V. 1975: Coccids as pests of park plants. Zashch. Rast. 3: 43-45 [in Russian].

Received June 21, 2010; revised and accepted October 12, 2010 